\title{
Dinâmica econômica mesorregional do setor agropecuário do estado do Ceará no período 2000-2015
}

\author{
José Ediglê Alcântara Moura \\ Francisco do O’ de Lima Júnior \\ Denis Fernandes Alves
}

\begin{abstract}
Resumo
A reestruturação produtiva alicerçada na inserção competitiva encontra na agropecuária do estado do Ceará sua reprodução como um dos signos da modernização econômica deste estado. Tal foi o suporte de condução da agricultura cearense nos últimos anos. Neste trabalho investiga-se a dinâmica econômica da agropecuária cearense durante o período de 2000 a 2015, considerando as suas distintas mesorregiões. Utilizou-se bancos de dados de órgãos oficiais públicos, como o IBGE. Os resultados mostram que as culturas frutícolas, como melão e melancia, obtiveram maior expansão, enquanto feijão e milho foram as culturas que mais arrefeceram em termos de área plantada e quantidade produzida. Na análise por mesorregião, as Mesorregiões Jaguaribe e Noroeste revelam-se como as de maior produção frutícola do estado, enquanto nos Sertões predomina a ovinocaprinocultura.
\end{abstract}

Palavras-chave | Ceará; dinâmica econômica mesorregional; modernização econômica; setor agropecuário.

Classificação JEL | O13 Q11 R11

Mesoregional economic dynamics of the agricultural sector in Ceará (2000-2015)

\begin{abstract}
The productive restructuring based on the competitive insertion finds in the Ceara's agriculture its reproduction as one of the several signs of the economic modernization on this Brazilian Northeastern State. Such was the driving support of Cearás agriculture in recent years. This work analyses the economic dynamics of agriculture in the State of Ceara during the period from 2000 to 2015, considering its different mesoregions. It was used a database of public official sources such as IBGE. The results of the investigation show that fruit crops, such as melon and watermelon, obtained larger expansion, while beans and maize were the crops that cooled the most in planted area and quantity produced. In the analysis by mesoregion, the
\end{abstract}


Jaguaribe and Northwest Mesoregions revealed to be the largest fruit producers in the State of Ceará, while in the Hinterland/Sertões predominate sheep and goat culture.

Keywords | Agricultural sector; Ceará; economic modernization; mesorregional economic dynamics.

JEL Classification | O13 Q11 R11

\section{Dinámica económica mesorregional del sector agropecuario del estado de Ceará en el período 2000-2015}

\section{Resumen}

La reestructuración productiva basada en la inserción competitiva encuentra en la agropecuaria del estado de Ceará su reproducción como uno de los signos de la modernización económica de este estado. Tal fue el apoyo a la conducción de la agricultura cearense en los últimos años. En este trabajo se analiza la dinámica económica de la agropecuaria cearense durante el período de 2000 a 2015, considerando sus diferentes mesorregiones. Se utilizó una base de datos de organismos públicos oficiales, como el IBGE. Los resultados muestran que los cultivos de frutas, como el melón y la sandía, tuvieron mayores expansiones, mientras que los frijoles y el maíz fueron los cultivos más refrescantes en el área plantada y la cantidad producida. En el análisis por mesorregión, las Mesorregiones Jaguaribe y Noroeste aparecen como las de mayor producción frutícola del estado, mientras que en los Sertões predomina la ganadería ovina y caprina.

Palabras clave | Ceará; dinámica económica mesorregional; modernización económica; sector agropecuario.

Clasificación JEL | O13 Q11 R11

\section{Introdução}

No contexto da evolução macroconjuntural da agricultura brasileira, o processo de desconcentração produtiva alicerçada na "modernização conservadora" na década de 1970 acabou por fortalecê-la mediante o argumento de eficiência da base técnica da produção, expresso nos elevados ganhos de produtividade. Tal movimento, por um lado, contribuiu para maior geração de divisas, mas, por outro, viabilizou o agravamento da estrutura fundiária, permitindo a reprodução das estruturas sociais vigentes (CANO, 2011; GRAZIANO DA SILVA, 1998; 1999).

Mediante as ações do II Plano Nacional de Desenvolvimento (II PND), baseados na estratégia de crescimento aliado ao endividamento externo e modificações acerca das orientações das políticas de desenvolvimento regional, a Região Nordeste foi inserida na dinâmica do planejamento deste período como fornecedora de bens 
intermediários para complementação da indústria nacional, em que no contexto de avanço das etapas finais do Processo de Substituição de Importações (PSI) fortaleceu o setor agropecuário nacional por meio da disponibilização de insumos necessários à expansão da capacidade produtiva.

Este processo havia começado ainda em fins dos anos 1960, com a modernização agrícola incentivada pelos programas implementados pelos governos militares. A dinâmica econômica nordestina ganhou novas feições pelo surgimento de espaços mais prósperos em meio ao quadro que tradicionalmente marcou a agropecuária regional, impactando na diminuição de postos de trabalho nas atividades monoculturas como o caso da cana-de-açúcar em seus maiores produtores regionais (Alagoas, Pernambuco e Paraíba), contrapondo-se à crescente participação da fruticultura irrigada, principalmente, nos vales do Rio São Francisco (Bahia e Pernambuco) e Vale do Açu (Rio Grande do Norte), além da produção de commodities em grãos (soja e milho), no oeste baiano, sul do Piaú e Maranhão, voltados especialmente para o mercado externo.

Dessa forma, a partir da configuração de diversidades marcadas por esta justaposição entre economias mais produtivas e competitivas e outras mais tradicionais, comprova-se os diferenciados padrões de desenvolvimento no Nordeste segundo por Araújo (2000). Assim, observa-se de fato uma aprofundada heterogeneidade na estrutura econômica regional: ao lado de uma agricultura mais intensiva em capital e, portanto, mais competitiva em espaços como os vales úmidos e nas áreas e complexos irrigados existe a convivência com problemas estruturais antigos e com espaços pouco capitalizados e focados na subsistência (LIMA JÚNIOR, 2014; MADEIRA, 2012).

Neste contexto, o presente trabalho investiga a dinâmica do setor agropecuário cearense no período de 2000 a 2015, tendo como referência as sete mesorregiões que compõem o estado do Ceará. A definição deste estado como estudo se justifica pela sua localização totalmente encravada no Sertão nordestino que proporcionam condições morfoclimáticas particulares, como alta insolação e baixa umidade do ar, estando seu território quase que na totalidade da demarcação do Semiárido (93\% de sua área, segundo delimitação da Sudene). Embora não seja objeto direto deste trabalho, é importante reaver que o caráter moderno e competitivo desta agricultura estimulada pela ótica da inserção externa contrasta com a permanência de antigos problemas como a estrutura agrária ainda concentrada e pouco estímulo a investimentos.

No campo das atividades induzidas pelas políticas e ações governamentais, além de condições para o desenvolvimento da fruticultura irrigada que, considerando o contexto climático, proporciona múltiplas safras anuais contribuindo para geração de divisas internacionais e economias de escala no processo produtivo. Segundo o Censo Agropecuário de 2006, o estado do Ceará possuía um total de 381.017 estabelecimentos agropecuários, ocupando 1.145.990 trabalhadores. O estado em 
estudo é formado preponderantemente por médias e grandes propriedades, sendo que $67,57 \%$ dos estabelecimentos têm menos de 10 hectares, indicando um perfil de concentração fundiária ${ }^{1}$.

Para alcançar o objetivo proposto, o trabalho está dividido em duas partes, além da introdução e considerações finais. Na primeira seção são traçadas algumas notas sobre a dinâmica econômica do setor agropecuário nordestino e cearense. $\mathrm{Na}$ segunda seção é apresentado de forma empírica o comportamento do setor agropecuário do Ceará em suas mesorregiões nos anos de 2000 a 2015.

Admitiu-se como questionamento problematizador a seguinte indagação: qual o comportamento do setor agropecuário cearense face ao contexto de inserção externa capitalista? A hipótese norteadora a ser seguida para resposta a tal questionamento é que com a reestruturação produtiva e maior abertura ao mercado consumidor internacional, as culturas secularmente cultivadas no Ceará perderam participação absoluta e relativa (arroz, feijão e milho), enquanto os ramos mais competitivos da fruticultura irrigada (melão, melancia e, até mesmo, castanha de caju) vêm passando paulatinamente a compor a pauta de produção agrícola com vistas a atender especialmente ao mercado externo.

Para a realização deste trabalho utilizou-se uma abordagem metodológica descritivo-explicativo, recorrendo-se a inicialmente uma revisão da literatura acerca do setor agropecuário nordestino e cearense. Seu delineamento é apresentado na parte sequencial a esta introdução. Posteriormente, foi apresentada a evolução do setor na economia cearense a partir da base de dados da Pesquisa Anual Municipal (PAM) e Pesquisa Pecuária Mensal (PPM), ambas contidas no banco de dados agregados do Sistema Instituto Brasileiro de Geografia e Estatística (IBGE) de Recuperação Automática (SIDRA), publicado pelo próprio IBGE. Em seguida, finaliza-se com as considerações finais.

\section{Notas metodológicas}

\section{Caracterização da área de estudo}

O Ceará é um dos nove estados que compõem a Região Nordeste do Brasil e possui 184 municípios, sendo sua capital Fortaleza. Sua posição geográfica tem como limites: ao Norte o Oceano Atlântico; ao Sul o estado de Pernambuco; a leste os estados do Rio Grande do Norte e Paraíba e a Oeste o estado do Piauí. O Ceará

\footnotetext{
1 O Censo Agropecuário de 2006 foi o último realizado pelo IBGE. Apesar do hiato temporal, seus dados dão parâmetros de análises acerca da configuração mais detalhada da agropecuária brasileira. Não foram trabalhados dados do Censo Agropecuário de 2017, pois sua divulgação se deu quando já se finalizava o presente trabalho.
} 
tem uma área geográfica de 148.825,6 $\mathrm{km}^{2}$, que corresponde a 9,57\% da área total da Região Nordeste e a 1,74\% do total do Brasil (IBGE, 2010).

De acordo com o Quadro 1, o estado possui sete mesorregiões ainda com elevada participação da população rural. Conforme se observa, as mesorregiões Noroeste, Norte, Sertões e Jaguaribe apresentam percentuais populacionais no meio rural acima de $40 \%$ que, para padrões de predomínio e crescimento urbano em vigência na atualidade, é considerado elevado. Nestas mesorregiões, a população urbana é respectivamente de $40,7 \%, 44,3 \%, 45,3 \%$ e $41,7 \%$.

\section{Quadro 1 - Mesorregiões do estado do Ceará: populações total, urbana e rural, 2010}

\begin{tabular}{|c|c|c|c|c|c|c|c|c|}
\hline \multirow[t]{3}{*}{ Mesorregiões } & \multirow[t]{3}{*}{$\begin{array}{c}\mathrm{N}^{\mathrm{o}} \mathrm{de} \\
\text { microrregiões }\end{array}$} & \multicolumn{2}{|c|}{$\begin{array}{c}\mathrm{N}^{\mathrm{o}} \text { de } \\
\text { municípios }\end{array}$} & \multicolumn{5}{|c|}{ População } \\
\hline & & \multirow[t]{2}{*}{ No. } & \multirow[t]{2}{*}{$\%$} & \multirow[t]{2}{*}{ Total } & \multicolumn{2}{|c|}{ Urbana } & \multicolumn{2}{|c|}{ Rural } \\
\hline & & & & & Hab. & $\%$ & Hab. & $\%$ \\
\hline Noroeste & 7 & 47 & 25,5 & 1.326 .771 & 787.722 & 59,3 & 539.049 & 40,7 \\
\hline Norte & 8 & 36 & 19,6 & 1.006 .582 & 560.520 & 55,7 & 446.062 & 44,3 \\
\hline $\begin{array}{l}\text { Metropolitana } \\
\text { de Fortaleza }\end{array}$ & 2 & 11 & 6,0 & 3.468 .137 & 3.367 .714 & 97,1 & 100.423 & 2,9 \\
\hline Sertões & 4 & 30 & 16,3 & 869.778 & 476.210 & 54,7 & 393.568 & 45,3 \\
\hline Jaguaribe & 4 & 21 & 11,4 & 528.274 & 308.245 & 58,3 & 220.029 & 41,7 \\
\hline Centro-Sul & 3 & 14 & 7,6 & 376.239 & 227.667 & 60,5 & 148.572 & 39,5 \\
\hline Sul Cearense & 5 & 25 & 13,6 & 876.600 & 618.479 & 70,5 & 258.121 & 29,5 \\
\hline Total & 33 & 184 & 100,0 & 8.452 .381 & 6.346 .557 & 75,1 & 2.105 .824 & 24,9 \\
\hline
\end{tabular}

Fonte: Censo Demográfico IBGE (2010).

A Figura 1 apresenta o mapa destas mesorregiões delineado os marcos físicos e, como é possível perceber, a de maiores dimensões é a mesorregião dos Sertões Cearenses. 


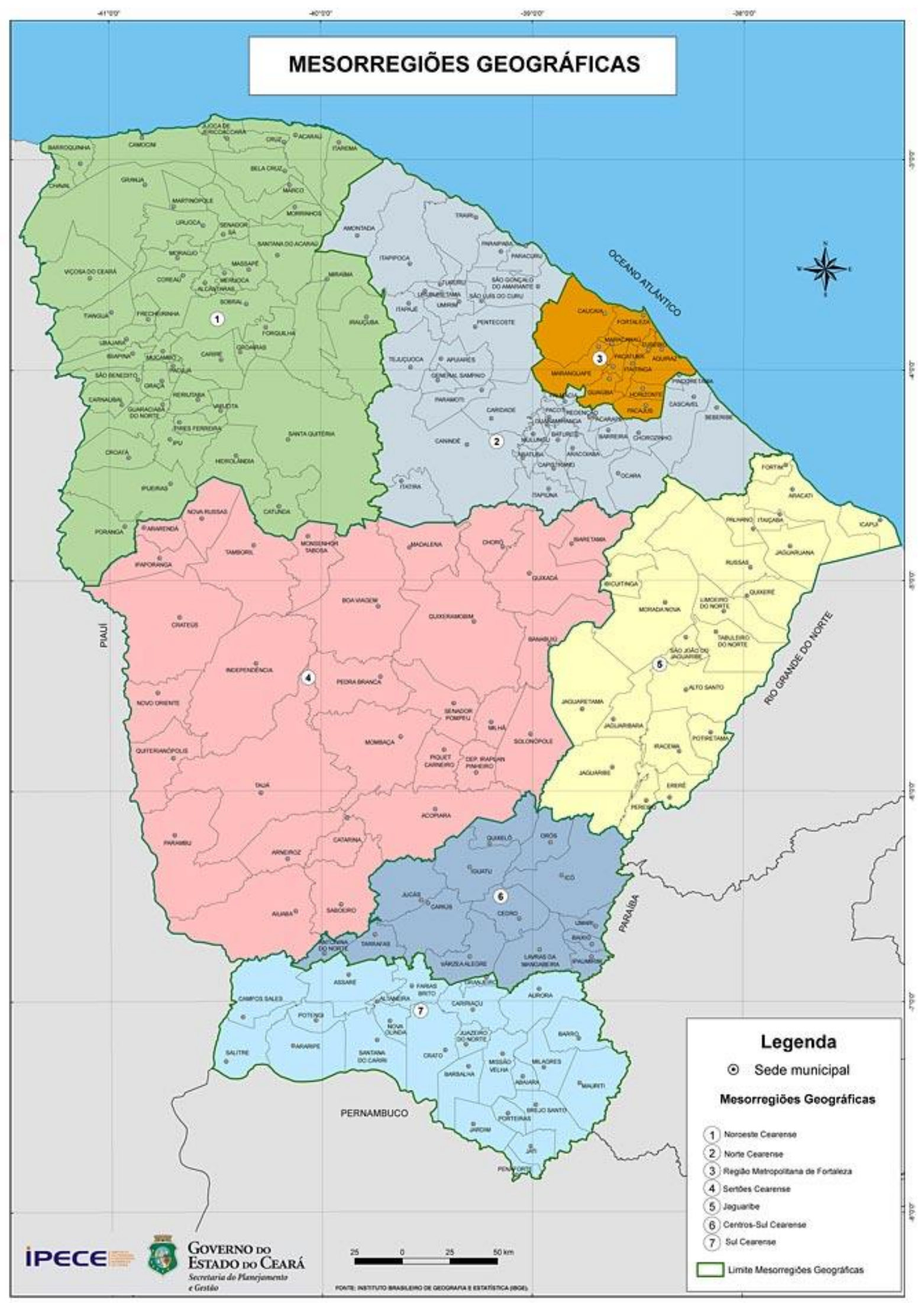

\section{Figura 1 - Mapa das mesorregiões cearenses}

Fonte: IPECE (2018). 
Segundo os dados demográficos de 2010, o Ceará possuía uma população total de 8.448.054 pessoas (4.118.065 homens e 4.329.989 mulheres). Sua densidade era de $56,76 \mathrm{hab} / \mathrm{km}^{2}$ e taxa de urbanização de 75,1\% (IPECE, 2015). O PIB per capita do referido ano era de $\mathrm{R} \$$ 6.149,00, com um Produto Interno Bruto (PIB) calculado em cerca de R\$50 bilhões. O Ceará possui a terceira maior economia da Região Nordeste do Brasil. Uma das atividades econômicas mais importantes é o turismo devido ao seu forte atrativo litorâneo, contando com cerca de 2 milhões de visitantes turistas ao ano. Ainda de acordo com o Instituto de Pesquisa e Estratégia Econômica do Ceará, o setor de serviços é o que compreende a maior riqueza gerada no Ceará: 70,24\%. O setor da Indústria gera outros 23,57\% da riqueza e agropecuária $6,19 \%$.

\section{Natureza e fontes dos dados.}

Metodologicamente se recorreu à base de dados da Pesquisa Pecuária Municipal (PPM) e Pesquisa Agrícola Municipal (PAM), disponibilizadas pelo Sistema IBGE de Recuperação Automática (Sidra) e extraídas do IBGE. Essa base de dados dispõe de informações para diferentes níveis territoriais, como região, unidade de federação, mesorregião e microrregião geográfica e município, sendo que se utilizou para este estudo os dados referentes ao estado do Ceará e suas mesorregiões.

\section{Método de análise}

Os dados empíricos do IBGE foram tabulados com a utilização do software MSExcel 2013 na elaboração das tabelas seguidas das respectivas análises provenientes de estatísticas descritivas. Para o comportamento da estrutura da pecuária foram analisados os dados da Pesquisa Pecuária Municipal (PPM) recorrendo à variável da flutuação de efetivo de animais. No que tange à Pesquisa Agrícola Municipal (PAM) dos anos de 2000, 2010 e 2015, recorreu-se às variáveis: oscilação da produção física das culturas agrícolas (ton) e áreas plantadas (ha) e produtividade média.

\section{Considerações acerca do contexto da agropecuária no estado do Ceará}

Caracterizada como a região brasileira mais árida e com baixa produtividade dos fatores empregados na agricultura, o Nordeste brasileiro tem-se configurado no cenário nacional como dependente de políticas públicas que objetivam amenizar os gargalos socioeconômicos provenientes de seu contexto histórico (CASTRO, 2012).

Desde a perda do dinamismo baseado na atividade agroexportadora, o açúcar inicialmente e a cotonicultura num segundo momento, a Região Nordeste não experimentou nenhuma outra atividade de grande rentabilidade. Assim, as 
principais explicações do entrave para o desenvolvimento econômico nessa região fundamentam-se em atividades agrícolas historicamente vinculadas ao mercado externo, áreas onde predominavam atividades de exploração pecuária extensiva, concentração fundiária e hídrica, predominância da reprodução mercantil do capital, além da baixa produtividade nos fatores de produção (CANO, 2011; MULLER, 1982).

Por volta de 1950, os diagnósticos advindos do pensamento clássico ricardiano das vantagens comparativas e que difundia uma divisão produtiva entre as nações são questionados pela contribuição de Raul Prebisch, Celso Furtado e outros estudiosos reunidos a partir da constituição da Comissão Econômica para a América latina (Cepal). Segundo os estudos da Cepal (1949), ao sistematizar o que denominou de deterioração dos termos de troca como uma elaboração crítica, observou-se que as economias cuja base produtiva pertence ao setor agropecuário melhoraram sua eficiência dado à absorção do progresso técnico neste segmento, que tende a provocar queda acentuada nos preços dos gêneros. Já nas economias industrializadas, caracterizadas pela estrutura de mercado oligopolizada, a tendência de queda nos preços é relativamente menor, impactando em uma significativa deterioração dos termos de intercâmbio a longo prazo, assim como uma nítida divisão regional do trabalho

Contrariando a tendência de subdesenvolvimento crônico imposto à periferia e sua superação a partir de uma bem definida divisão internacional do trabalho, a Cepal elabora prognósticos de superação pelo estímulo à industrialização planejada, bem como um conjunto de políticas públicas de modernização das estruturas econômicas. No caso brasileiro, a arrancada industrial via substituição de importações ganhou fôlego e para o caso das assimetrias regionais, o mesmo planejamento com a ação estatal preponderante foi o condutor (BIELSCHOWSKY, 2004).

Derivando deste contexto, é elaborado um conjunto de diretrizes para a superação do problema de debilidade da economia nordestina por meio do Grupo de Trabalho para o Desenvolvimento do Nordeste (GTDN), liderado por Celso Furtado. Dentre outros elementos, as recomendações do GTDN apontavam para a superação do atraso econômico com medidas reestruturantes que superavam a solução aos problemas hídricos da região.

O atraso socioeconômico do Nordeste estava explicado na formação histórica da região, com sistemas produtivos de baixa rentabilidade e expelidos à dinâmica do mercado externo (cana-de-açúcar, pecuária, algodão e agricultura de subsistência), marcado pela elevada concentração de terras (controladas pelos latifundiários das zonas semiárida e úmida do sertão), além das políticas cambial e de subsídios definidos nas políticas de estímulo à industrialização, favoráveis aos industriais do Centro-Sul. As suas linhas gerais se pautavam em pontos como o papel do Nordeste na economia brasileira, os elementos dinâmicos da região, o aspecto 
socioeconômico das secas e trazia um plano de ação. Neste, a promoção de mudanças na agricultura estava presente com destaque, tendo em vista que, dentre outros, estavam medidas diretas, como melhoria dos solos e recursos hídricos no Semiárido, reorganização da economia e frentes de colonização, e estratégia para oferta de alimentos (LIMA JÚNIOR, 2014).

Deste modo, consolida-se no final dos anos 1950 e início dos 1960 um conjunto de institucionalidades objetivando a transformação nordestina, surgindo dessa forma a Superintendência do Desenvolvimento do Nordeste (Sudene), que proporcionou a consolidação de um aparato de medidas e políticas de desenvolvimento regional, pautadas também em investimentos públicos em infraestrutura (DINIZ, 2009; PACHECO, 1998)

Com as mudanças instauradas pelo Regime Militar, as ações pensadas neste momento sofrem alterações e as propostas de desenvolvimento regional da Sudene avançaram na diversificação da estrutura produtiva regional nos anos $1970 \mathrm{com}$ base nas ações do II Plano Nacional de Desenvolvimento Nacional (II PND). Aqui, a busca de reduzir as disparidades regionais elencou grandes projetos de infraestrutura. No campo da dinamização das atividades agrícolas, ocorreram ações como a criação de "polos dinâmicos", a exemplo do polo agroindustrial de Juazeiro/Petrolina no Vale do São Francisco e expansão da fronteira agrícola que na região implicará em reordenamentos na sua porção oeste, em áreas dos estados do Maranhão, do Piauí e da Bahia (GOMES, 2010).

Assiste-se, a partir de então, a formação de espaços mais produtivos por meio da dinamização de polos irrigados, com a produção de commodities orientadas especialmente para o mercado externo (LIMA, 2005; LIMA JÚNIOR, 2014). E, com esta dinâmica, a introdução de máquinas e insumos modernos, em que em alguns aspectos revelou as faces contraditórias da modernização proposta: ao passo que eleva a produtividade, pode promover a precarização das relações de trabalho presentes no meio rural (VALE; SILVA FILHO; SILVA, 2010).

Ainda assim para as políticas implementadas a partir de então, os principais fundamentos que justificaram essas transformações e deram fôlego à condução de ações e programas de estímulo se dirigem ao potencial do agronegócio do Nordeste elegendo fatores favoráveis fortes como: i) a mão de obra abundante e de menor remuneração; e ii) as condições climáticas de sol o ano todo e baixa umidade, sendo, portanto, privilegiadas por permitirem múltiplas safras anuais, especialmente no segmento frutícola (EVANGELISTA, 1996; SOUSA, 2010).

Como derivação destes fatores, a irrigação no Nordeste tem sido incentivada por diversas políticas e instituições no intuito de modernizar a agricultura, aumentar a produção e, por fim, gerar renda em regiões economicamente estagnadas. Como já explorado aqui, secularmente as iniciativas da questão hídrica e agrícola tinham outro direcionamento, apontando a seca como principal questão a ser superada e 
não avançado em pontos como novas culturas, mudanças pelo acesso a crédito e tecnologias, dentre outros.

Um salto se deu com a institucionalidade implantada dos anos 1950 em diante ${ }^{2}$, que avançam na execução da política de irrigação delineada com a instituição do Grupo Executivo de Irrigação e Desenvolvimento Agrário (Geida), com o Programa Plurianual de Irrigação, além do Programa de Integração Nacional, que financiou a primeira fase do Programa Nacional de Irrigação, seguidos pelos dois Planos Nacionais de Desenvolvimento, em 1972 e 1979. Entre esses dois, destacou-se o Programa de Desenvolvimento do Nordeste (Polonordeste), em 1974, que teve efeitos na configuração da área de agricultura da parte oeste nordestina, ao dinamizar a produção agrícola de grãos.

Posteriormente foi criado o Programa de Irrigação do Nordeste (Proine), em 1986, e instituído o Programa de Apoio ao Desenvolvimento da Fruticultura Irrigada no Nordeste $^{3}$, em 1996. (ABLAS, 1988; BUAINAIN; GARCIA, 2013; RAMOS, 2007; SILVA, 2003). Ainda assim, tal evolução passou por um processo de inflexão por meio do arrefecimento do crescimento econômico nos anos 1980. Tal quadro foi resultante da crise econômica desencadeada pela elevação do endividamento externo, associado à impossibilidade de obtenção de saldo de divisas por meio das exportações no contexto de restrição do crédito internacional, crescente instabilidade inflacionária que repercutiu negativamente na agropecuária nacional, uma vez que as políticas para esse setor se tornaram mais tímidas com redução do crédito e eliminação dos subsídios (VALOIS, 2012). Como as transformações na agricultura do Nordeste foram concebidas a partir da modernização para o mercado externo, os efeitos ficaram mais restritos durante este período.

A reprodução destes movimentos na economia cearense, como um caso específico da economia nordestina, seguirá a regularidade mais geral acima apresentada até os anos 1980 quando mudanças do ponto de vista da gestão, política e economia são observadas. O quadro de reformas mais gerais objetivou promover uma modernização, colocando o Ceará no conjunto de estados como plataforma atrativa de investimentos, seguindo receituários direcionados à superação de gargalos sociais e desigualdades manifestados no acesso à educação, saúde e saneamento. Este processo teve sua sequência na gestão política do estado por mais de duas décadas, consolidando um paradigma de governo e política pública. Seus reflexos no campo

\footnotetext{
2 A montagem gradativa desta institucionalidade se deu, dentre outros, pela implantação da Companhia Hidroelétrica do São Francisco (CHESF) em 1948, da Comissão do Vale do São Francisco, substituída pela Companhia de Desenvolvimento do Vale do São Francisco (Codevasf), além da já mencionada Sudene.

${ }^{3}$ No entanto, a prática da irrigação, exclusivamente, não é suficiente para promover um sistema sustentável
aos agricultores, já que em muitos casos estes projetos dependem economicamente da tutela do estado. A
irrigação pública, segundo Silva (2003), sempre teve forte suporte da esfera federal de governo com muitos
projetos não tendo alcançado as metas estabelecidas e não apresentando condições de sustentabilidade.
} 
das atividades econômicas se direcionaram a um modelo de promoção do desenvolvimento centrado no estímulo ao tripé da agricultura irrigada, da indústria incentivada e do turismo. A seção seguinte busca evidenciar os movimentos decorrentes deste modelo na agropecuária. Nos outros dois segmentos do tripé, observou-se o avanço na modernização da indústria tradicional que marcava a estrutura produtiva do estado (calçados, têxtil e alimentos) e a intensificação dos serviços de receptivo com a consolidação de um padrão atrativo no turismo, concebido nos moldes de litorâneos de uma imensa oferta de roteiros de praias e atividades desdobradas ${ }^{4}$.

Neste contexto, no segmento da agropecuária, considera-se que o Ceará possui uma série de vantagens comparativas e/ou possíveis potencialidades para o desenvolvimento do setor, como a proximidade geográfica com o mercado consumidor internacional que favorece a inserção da fruticultura irrigada em áreas denominadas de agropolos (ABLAS, 1988; GOMES, 2010).

Entretanto, é importante lembrar que a maior parte geográfica da unidade da federação analisada é compreendida pelos sertões cearenses, que reproduzem os gargalos socioeconômicos com a predominância da agricultura de subsistência, intensiva em mão de obra e com baixa integração ao setor externo, identificando, assim, que a relativa modernização agrícola cearense induz a um processo de intensa seletividade ao longo dos anos, em vez de atenuá-la (MADEIRA, 2012).

Por outro lado, ao beneficiar a dinâmica econômica, as ocupações criadas em segmentos agrícolas de fruticultura irrigada são caracterizadas como mais modernas e capital/intensivas tendo em vista o uso de maquinário, bem como a aplicação de técnicas de manejos, uso de sementes e mudas transgênicas. Apresenta-se, portanto, um caráter contraditório considerando que, ao exigir elevada capitalização, não se trata necessariamente do perfil de atividade que responda aos imperativos de transformação que inclua os fatores que caracterizam a atividade agrícola cearense.

Segundo os dados da Relação Anual de Informações Sociais (RAIS), o estado do Ceará, no ano de 2015, contava com um total de 27.522 postos formais de trabalho no setor agropecuário, sendo que a mesorregião de Jaguaribe ${ }^{5}$ abarcava $39,39 \%$ e a mesorregião Metropolitana de Fortaleza com 24,03\% do total de ocupações formais agrícolas $^{6}$. As mesorregiões Centro-Sul, Sul Cearense e Sertões, juntos, ocupavam

\footnotetext{
${ }^{4}$ No caso da indústria incentivada concebidas neste tripé, trabalhos como os de Lima Júnior (2014) e Silva Filho (2014) analisam seus efeitos e desdobramentos. Já no caso do turismo, investigações sobre os efeitos de sua concepção e efeitos são estudados por Dantas (2002).

${ }^{5}$ Desagregando a nível mesorregional observou-se que a atividade do cultivo de melão gerou 5.760 postos formais de trabalho (RAIS, 2015).

${ }^{6} \mathrm{O}$ estado do Ceará possui, na divisão do Instituto Brasileiro de Geografia e Estatísticas (IBGE), sete mesorregiões, sendo elas: Noroeste Cearense, Norte Cearense, Metropolitana de Fortaleza, Jaguaribe, Centro-Sul Cearense e Sul Cearense.
} 
apenas 7,81\% dos vínculos formais do estado (RAIS, 2015) indicando, ainda, uma limitação do mercado de trabalho agrícola estadual. O perfil socioeconômico e sociodemográfico dos ocupados no setor em estudo apontam intensa seletividade por sexo e idade, com melhoria relativa do nível de instrução dos ocupados em contraditoriamente ao esperado, redução dos salários nominais dos assalariados ${ }^{7}$ (MOURA; PAIVA; 2016).

\section{Dinâmica mesorregional do setor agropecuário cearense no período de 2000 a 2015}

\section{A produção agrícola cearense e suas espacialidades mesorregionais}

Quanto à participação relativa das culturas agrícolas por mesorregiões no estado do Ceará, percebe-se ao longo do período em estudo queda expressiva das culturas que historicamente lançaram as bases para a formação econômica estadual, a exemplo do algodão. Esta produção, ao longo dos anos em análise, vem perdendo participação em todas as mesorregiões cearenses. A Tabela 1 apresenta a evolução dos segmentos que serão aqui evidenciados.

À medida que culturas tradicionais foram declinando, a participação da fruticultura foi se ampliando permitindo induzir uma substituição de cultivos no bojo da modernização acima aludida. Observando inicialmente a distribuição das culturas, alguns padrões se destacam. No caso da produção de banana, percebe-se sua concentração em duas mesorregiões: Norte e Jaguaribe, sendo que a primeira em 2000 participou com 11,4\%, chegando 13,5\% em 2010 e reduzindo para $11,7 \%$ em 2015. Na segunda mesorregião em análise para o ano de 2000 , tem-se um total de 4,3\%, passando 2010 para 7,8\% e extraordinariamente chegando em 2015 com 26,7\%. O Sul Cearense percebe-se que em 2015 participa com 28,1\%.

Nos Sertões Cearenses, a atividade tradicional de plantio de algodão analisada vem perdendo composição na sua pauta de produção, alcançando pífios $0,2 \%$ no último ano verificado. Tal comportamento percebido como a maior transição entre o padrão agrícola tradicional que, no caso do algodão se comprometeu pela praga do bicudo e por sua baixa competitividade quando das tentativas de reabilitação, e o atual padrão concebido pelo tripé modernizante.

No que tange à castanha de caju, percebe-se que as mesorregiões Norte e Noroeste são as que mais produziram em toneladas nos anos analisados, sendo que a primeira

\footnotetext{
7 É importante mencionar as restrições de análises sobre o mercado de trabalho agrícola pautadas exclusivamente em dados da RAIS, tendo em vista que este banco de informações se constitui em registros unicamente formais. Este setor tem forte participação de trabalhadores não formalizados, principalmente na Região Nordeste onde a informalidade é característica comum a todas as atividades econômicas (LIMA JÚNIOR, 2014)
} 
no ano de 2000 obteve 33,13\%, caindo em 2010 para 31,3\% e atingindo 42,8\% em 2015. Na segunda mesorregião, percebe-se sensível queda ao longo dos anos, sendo que em 2000 tem-se uma participação de 40,9\% passando para 40,3\% e atingindo, em 2015, 38,9\% toneladas. As demais mesorregiões pouco participam, a exemplo dos Sertões, que ano de 2015 registrou apenas 1\% na participação física de castanha de caju no estado do Ceará. Conforme destaca Lima Júnior (2014, p. 105-106), a castanha de caju nestas mesorregiões tinha exploração inicialmente extrativista, passando de meados dos anos 2000 em diante a ser estimulado o plantio de forma competitiva.

No caso da cultura do mamão, a mesorregião Noroeste Cearense é a que mais contribui na produção no ano de 2000 atingindo 43,7\% do total da participação. No entanto, em 2015, a mesorregião Jaguaribe destaca-se como a maior produtora, alcançando 63,6\% do total da produção de mamão no estado do Ceará, sendo um dos efeitos do processo de estímulo e ordenamentos da fruticultura irrigada. A mesorregião em questão foi uma das priorizadas no processo de diversificação de culturas irrigadas, seguindo os caminhos que consolidam esta como a área de maior produtividade na fruticultura irrigada no Ceará.

Para a manga, tem-se a mesorregião Sul Cearense como a maior produtora em 2015, alcançando 20,5\% do total, seguindo das mesorregiões Jaguaribe e Noroeste que ocupam aproximadamente $18 \%$ do total da produção desta fruta no estado. A novidade nessa cultura é a inserção da mesorregião Sul, que é uma das beneficiadas em destaque pelos programas e ações da Secretaria de Agricultura Irrigada do Estado, por meio do Instituto Agropolos, almejando a diversificação de sua agricultura, com destaque para os municípios de Mauriti e Missão Velha. 
Tabela 1 - Participação relativa (\%) das culturas agrícolas em ton. nas mesorregiões cearenses nos anos de 2000 a 2015 (Ceará=100)

\begin{tabular}{|c|c|c|c|c|c|c|c|c|}
\hline Discriminação & Anos & Noroeste & Norte & Metropolitana & Sertões & Jaguaribe & $\begin{array}{c}\text { Centro- } \\
\text { Sul } \\
\end{array}$ & $\begin{array}{c}\text { Sul } \\
\text { Cearense } \\
\end{array}$ \\
\hline Algodão & 2000 & 16,5 & 57,3 & --- & 23,8 & --- & 0,37 & --- \\
\hline \multirow[t]{2}{*}{ arbóreo } & 2010 & 40,3 & 5,7 & --- & 54,0 & --- & --- & --- \\
\hline & 2015 & --- & --- & --- & --- & --- & --- & --- \\
\hline Algodão & 2000 & 8,0 & 5,7 & 1,2 & 43,3 & 26,1 & 9,0 & 6,5 \\
\hline \multirow[t]{2}{*}{ Herbácio } & 2010 & 6,1 & 1,1 & --- & 35,7 & 22,3 & 29,0 & 7,8 \\
\hline & 2015 & --- & --- & --- & --- & --- & --- & --- \\
\hline \multirow[t]{3}{*}{ Banana } & 2000 & 11,4 & 69,0 & 7,0 & 1,7 & 4,3 & 2,1 & 4,5 \\
\hline & 2010 & 13,5 & 62,7 & 6,4 & 1,5 & 7,8 & 1,9 & 6,2 \\
\hline & 2015 & 11,7 & 27,8 & 1,4 & 0,2 & 26,7 & 4,3 & 28,1 \\
\hline Castanha de & 2000 & 33,3 & 40,9 & 4,6 & 1,7 & 19,0 & 0,1 & 0,5 \\
\hline \multirow[t]{2}{*}{ Caju } & 2010 & 31,3 & 40,3 & 4,8 & 1,6 & 21,3 & -- & 0,9 \\
\hline & 2015 & 42,8 & 38,9 & 8,0 & 1,0 & 8,3 & --- & 0,7 \\
\hline \multirow[t]{3}{*}{ Mamão } & 2000 & 43,7 & 18,4 & 22,8 & 1,4 & 12,8 & 0,1 & 0,8 \\
\hline & 2010 & 49,6 & 18,2 & 12,4 & 4,0 & 12,7 & --- & 3,1 \\
\hline & 2015 & 24,9 & 7,5 & 0,8 & 1,7 & 63,6 & 0,3 & 1,9 \\
\hline \multirow[t]{3}{*}{ Manga } & 2000 & 31,6 & 30,5 & 11,7 & 6,7 & 3,6 & 2,3 & 13,6 \\
\hline & 2010 & 28,1 & 28,9 & 10,2 & 5,0 & 10,5 & 1,9 & 15,4 \\
\hline & 2015 & 18,1 & 30,2 & 8,5 & 3,8 & 18,3 & 1,2 & 20,5 \\
\hline \multirow[t]{3}{*}{ Arroz } & 2000 & 11,4 & 9,0 & 1,5 & 6,3 & 11,3 & 32,4 & 27,7 \\
\hline & 2010 & 20,7 & 11,8 & 0,6 & 5,6 & 23,5 & 21,8 & 15,9 \\
\hline & 2015 & 1,70 & 6,17 & 0,2 & 0,02 & 75,5 & 15,3 & 1,4 \\
\hline \multirow[t]{3}{*}{ Feijão } & 2000 & 22,2 & 15,7 & 1,5 & 30,9 & 10,9 & 5,9 & 12,9 \\
\hline & 2010 & 29,3 & 18,9 & 1,7 & 27,9 & 5,6 & 5,9 & 10,7 \\
\hline & 2015 & 24,5 & 22,0 & 1,7 & 30,7 & 7,6 & 3,1 & 9,4 \\
\hline \multirow[t]{3}{*}{ Mandioca } & 2000 & 45,8 & 32,1 & 3,9 & 2,7 & 3,0 & 0,2 & 12,4 \\
\hline & 2010 & 39,8 & 33,0 & 6,9 & 1,9 & 7,7 & 0,1 & 10,6 \\
\hline & 2015 & 43,9 & 31,8 & 3,3 & 0,8 & 3,7 & 0,1 & 16,6 \\
\hline \multirow[t]{3}{*}{ Milho } & 2000 & 18,2 & 14,3 & 1,3 & 34,0 & 7,4 & 6,2 & 18,6 \\
\hline & 2010 & 23,0 & 16,0 & 1,2 & 31,1 & 2,8 & 7,8 & 18,1 \\
\hline & 2015 & 18,0 & 34,0 & 14,1 & 33,5 & 2,8 & 5,7 & 23,0 \\
\hline \multirow[t]{3}{*}{ Melão } & 2000 & --- & 12,4 & 0,9 & 0,1 & 86,5 & --- & --- \\
\hline & 2010 & --- & -- & 0,2 & -- & 99,8 & --- & --- \\
\hline & 2015 & --- & --- & 0,8 & 0,00 & 99,92 & --- & --- \\
\hline \multirow[t]{3}{*}{ Melancia } & 2000 & 50,2 & 12,3 & --- & 0,7 & 36,8 & --- & --- \\
\hline & 2010 & 35,3 & --- & 0,1 & --- & 64,2 & 0,4 & --- \\
\hline & 2015 & 26,8 & 0,3 & 0,6 & 2,5 & 66,0 & -- & 3,9 \\
\hline
\end{tabular}

Fonte: PAM/IBGE (2000; 2010; 2015).

No que tange às culturas tradicionais como arroz, feijão, mandioca e milho tem-se expressivas variações, conforme observa-se na Tabela 1. No caso do arroz, em 2000 a mesorregião Centro-Sul era a maior produtora (32,4\%), seguida do Sul Cearense $(27,7 \%)$. Tal resultado vem a se modificar no ano de 2010 , sendo que a mesorregião maior produtora passa a ser Jaguaribe (23,5\%), seguida do Centro-Sul e Noroeste 
cearenses com mais de $20 \%$ cada uma da produção estadual de arroz. No ano de 2015, a mesorregião Jaguaribe alcança maior produção (75,5\%), ficando em segundo lugar o Centro-Sul com 15,3\%. Manifesta-se, aqui, mais uma vez, as transformações na agricultura do estado no sentido da substituição da cultura tradicional pelas incentivadas num padrão mais modernizado. A produção de arroz na mesorregião Jaguaribe, ainda que não se compare com a fruticultura, é também mais mecanizada e beneficiada pelos programas de irrigação.

No que se refere ao feijão, uma das culturas mais tradicionais da agricultura do estado, em 2000, a mesorregião dos Sertões Cearenses era a maior produtora $(30,9 \%)$, em $2010,(27,9 \%)$ e em 2015 , mesmo com as estiagens ainda se configura com maior participação $(30,7 \%)$. As segundas maiores produtoras são as mesorregiões Noroeste e Norte cearenses, sendo que em 2015 participam respectivamente $\operatorname{com} 24,5 \%$ e $22,0 \%$ do total de feijão em toneladas no estado.

Ainda nas culturas tradicionais, o caso da mandioca, a mesorregião Noroeste se configura como maior produtora em 2000 (45,8\%), 2010, (39,8\%), 2015 (43,9\%). A mesorregião que menos produz é a Centro-Sul Cearense, com menos de $1 \%$ do total da mandioca cultivada no estado. Nestas culturas, a organização produtiva é calhada à produção em regime de agricultura familiar. Para o milho, a mesorregião Sertões Cearenses se destaca como a maior produtora do estado cearense, alcançando uma participação de 34\% em 2000, 31,1\% em 2010 e 33,5\% em 2015. Em segundo lugar está a mesorregião Norte com 34\% do total de milho produzido em âmbito estadual em 2015. Conforme se observa, estas culturas têm uma ocupação territorial em áreas em que a agricultura é menos capitalizada, como o caso da mesorregião dos Sertões Cearense.

No âmbito da produção mais ligada às atividades mais induzidas pelos programas de irrigação expostos na Tabela 1, como a produção frutícola de melão, percebe-se que a mesorregião Jaguaribe se configura como a maior produtora ao longo dos anos da fruta, sendo que em 2015 participou com 99,92\% da produção estadual, produção direcionada quase que exclusivamente à exportação. Este polo de fruticultura irrigada, localizado na divisa do estado do Ceará com o Rio Grande do Norte, apresenta-se como um continum territorial do polo já consolidado neste último estado, em Assú-Mossoró e especializado na produção de melões para exportação.

No que tange à produção de melancia, as mesorregiões Jaguaribe e Noroeste são as

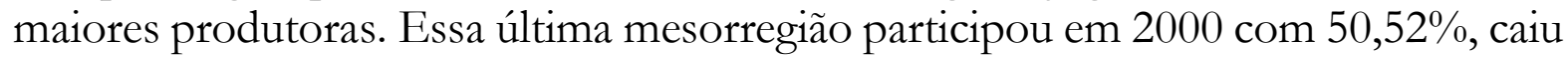
em 2010 para $35,3 \%$ e atingiu $26,8 \%$ em 2015. Suas quedas foram compensadas pelos aumentos no Jaguaribe que em 2000 participou com 36,8\%, 2010 aumentou para 64,2\%, atingindo em 2015 um total de $66 \%$ do total de melancias produzidas no estado. 


\section{Os diferenciais de produtividade nas culturas agrícolas cearenses ${ }^{8}$}

No intuito de compreender a dinâmica mais geral do setor agrícola estadual a partir dos elementos postos na seção anterior, e como forma de balizar um comparativo entre o que se denomina de culturas mais tradicionais de um lado e as mais competitivas do outro, serão apresentadas as evoluções estaduais da produção de melão e melancia no primeiro caso, e de feijão e milho, para o segundo.

Em relação à produção de melão no Ceará, os dados da Pesquisa Pecuária Municipal (PPM) expostos na Tabela 2 mostram que ocorreram, ao longo dos anos selecionados, variações expressivas. Observou-se que nos anos de 2000 e 2001 registraram-se as menores produtividades, respectivamente de 21,99 e 23,79 toneladas por hectare plantado, e a maior $(30,26 \mathrm{t} / \mathrm{h})$ no ano de 2014.

Tabela 2 - Produção de melão por área plantada (em hectares), Ceará, 2000 a 2015

\begin{tabular}{cccc}
\hline Ano & $\begin{array}{c}\text { Área Plantada } \\
\text { Hectares }\end{array}$ & $\begin{array}{c}\text { Produção } \\
\text { Toneladas }\end{array}$ & $\begin{array}{c}\text { Produção } \\
\text { Toneladas/Hectare }\end{array}$ \\
\hline 2000 & 2.016 & 44.338 & 21,99 \\
2001 & 3.002 & 71.442 & 23,79 \\
2002 & 3.842 & 92.047 & 23,95 \\
2003 & 4.119 & 99.496 & 25,78 \\
2004 & 4.394 & 109.566 & 24,94 \\
2005 & 4.951 & 117.937 & 23,82 \\
2006 & 6.629 & 165.333 & 24,94 \\
2007 & 6.923 & 173.378 & 25,04 \\
2008 & 6.803 & 170.424 & 25,05 \\
2009 & 4.888 & 124.157 & 25,40 \\
2010 & 5.431 & 153.161 & 28,20 \\
2011 & 5.629 & 143.466 & 25,49 \\
2012 & 7.794 & 219.309 & 28,14 \\
2013 & 7.329 & 212.362 & 28,98 \\
2014 & 7.349 & 222.391 & 30,26 \\
2015 & 4.482 & 111.487 & 24,87 \\
\hline
\end{tabular}

Fonte: PAM/IBGE (2000; 2015).

Cabe observar que no ano 2000, primeiro da série, a produtividade por hectare foi de 21,99 toneladas. No último ano analisado, elevou-se para 29,20 toneladas. Diante do exposto, é possível garantir apenas que a produtividade oscila ao longo dos anos

\footnotetext{
8 A produtividade aqui está relacionada apenas à quantidade produzida por área plantada, sem, contudo, levar em consideração outros fatores que a influenciam, tais como número de máquinas utilizadas no plantio e na colheita, precipitações pluviométricas, indicadores de utilização de inseticidas e pesticidas, dentre outros.
} 
sendo estimulado principalmente pelas exportações. Conforme apontam os dados da Secretaria de Comércio Exterior (SECEX), no grupo de frutas, a produção de melões está entre as 10 primeiras mais exportadas pelo país desde 2001, sendo que no Ceará há uma evolução positiva, saindo da $11^{a}$ posição para a terceira de produto mais exportado do estado entre o período analisado?. Isso evidencia que o reordenamento prevalecendo esta cultura sinaliza para imprimir uma agricultura de atendimento às demandas externas, pautada no princípio da inserção competitiva global conforme atesta Macedo (2010).

Em relação à área plantada, observa-se sua elevação nos anos da série. No primeiro, foram registrados, segundo dados da Pesquisa Agrícola Municipal, 2.016 hectares plantados no estado. Houve oscilações ao longo da série, com registro de maior área plantada no ano de 2012 (7.794). Para o último ano analisado, tem-se 111.487 hectares plantados. No que tange à produção em 2000, o Ceará produziu 44.338 toneladas de melão, passando para 153.161 ton em 2010 e atingindo 111.487ton em 2015, uma variação negativa de $27,21 \%$ entre estes dois últimos anos.

Tabela 3 - Produção de melancia por área plantada (em hectares), Ceará, 2000 a 2015

\begin{tabular}{lccc}
\hline Ano & $\begin{array}{c}\text { Área Plantada } \\
\text { Hectares }\end{array}$ & $\begin{array}{c}\text { Produção } \\
\text { Toneladas }\end{array}$ & $\begin{array}{c}\text { Produção } \\
\text { Toneladas/Hectare }\end{array}$ \\
\hline 2000 & 340 & 1.306 & 3,84 \\
2001 & 367 & 5.710 & 15,56 \\
2002 & 311 & 5.521 & 17,75 \\
2003 & 272 & 7.973 & 29,31 \\
2004 & 463 & 15.337 & 33,13 \\
2005 & 677 & 22.065 & 32,59 \\
2006 & 1.066 & 34.794 & 32,64 \\
2007 & 1.218 & 39.720 & 32,61 \\
2008 & 1.473 & 56.285 & 38,21 \\
2009 & 1.465 & 51.281 & 35,00 \\
2010 & 1.223 & 50.324 & 41,14 \\
2011 & 1.621 & 56.910 & 35,10 \\
2012 & 2.089 & 75.442 & 36,11 \\
2013 & 2.024 & 68.895 & 34,00 \\
2014 & 1.859 & 82.424 & 44,33 \\
2015 & 1.391 & 35.805 & 25,74 \\
\hline
\end{tabular}

Fonte: Elaboração Própria. PAM/IBGE (2000; 2015).

\footnotetext{
${ }^{9}$ Os valores exportados saltam de U\$S $11.315 .014,00$ para U\$S 88.710.968,00 respectivamente entre 2001 e 2015 (SECEX, 2017).
} 
No tocante à produção de melancia, outra atividade prioritariamente voltada para o mercado externo, os dados da plotados na Tabela 3 mostram que durante os anos selecionados ocorreram variações expressivas. Observou-se que o ano de 2000 registrou a menor produtividade média $(3,84 \mathrm{t} / \mathrm{h})$ e maior no ano de 2010 $(41,14 t / h)$.

Cabe afirmar que durante os anos selecionados a área plantada cresceu substancialmente, sendo que em 2000 registram 340 hectares plantados, passando para 1.223 em 2010, alcançando em 2015 em termos absolutos um total de 1.391 hectares. No que tange a produção, no ano de 2000 registrou-se um total de 1.306 toneladas, passando para 50.324 toneladas em 2010 e vindo atingir em 2015 um total de 35.805 toneladas. Esses dados apontam a reprodução da mesma dinâmica que o melão: uma cultura de direcionamento ao mercado externo, sendo condutora de transformações na agricultura estadual.

No âmbito das culturas mais tradicionais, a Tabela 4 mostra a produção de feijão no Ceará. Os dados apontam que no período 2000-2015 a produtividade média dessa cultura caiu quase que interruptamente, a menor produtividade média é registrada em 2013, com 0,12 t/ h e maior no ano de 2006 com 0,46 t/h.

Tabela 4 - Produção de feijão por área plantada (em hectares), Ceará, 2000 a 2015

\begin{tabular}{lccc}
\hline Ano & $\begin{array}{c}\text { Área Plantada } \\
\text { Hectares }\end{array}$ & $\begin{array}{c}\text { Produção } \\
\text { Toneladas }\end{array}$ & $\begin{array}{c}\text { Produção } \\
\text { Toneladas/Hectare }\end{array}$ \\
\hline 2000 & 570.027 & 196.696 & 0,34 \\
2001 & 525.965 & 87.661 & 0,17 \\
2002 & 597.221 & 199.493 & 0,33 \\
2003 & 599.096 & 208.792 & 0,35 \\
2004 & 566.191 & 129.821 & 0,23 \\
2005 & 494.132 & 132.366 & 0,27 \\
2006 & 547.178 & 253.258 & 0,46 \\
2007 & 561.220 & 129.512 & 0,23 \\
2008 & 592.716 & 252.741 & 0,43 \\
2009 & 610.267 & 129.827 & 0,21 \\
2010 & 464.636 & 83.286 & 0,18 \\
2011 & 600.137 & 264.205 & 0,44 \\
2012 & 456.787 & 52.721 & 0,12 \\
2013 & 318.952 & 55.630 & 0,17 \\
2014 & 403.666 & 108.998 & 0,27 \\
2015 & 404.701 & 67.350 & 0,17 \\
\hline
\end{tabular}

Fonte: Elaboração Própria. PAM/IBGE (2000; 2015).

Em 2000, o Ceará produziu um total de 196.696 toneladas passando em 2010 para 83.286 e atingindo em 2015 em termos absolutos 67.350. Como não se trata 
prioritariamente de uma atividade irrigada, tal resultado deve-se às longas estiagens que ocorreram nos últimos anos no estado, que diminuiu consideravelmente a produção em culturas de sequeiro que dependem das precipitações pluviométricas. No tocante à área plantada, em 2000 auferiu-se um total de 570.027 ha, passando em 2010 para 464.636 ha e chegando em 2015 a apresentar em termos absolutos 404.701 ha.

No tocante à produção de milho no Ceará, percebe-se as oscilações no nível de produtividade média da cultura analisada. O menor nível de produtividade é observado no ano de 2012 (0,23\%) e maior em 2011 (1,26\%). No ano 2000, a relação área plantada/hectare foi de 1,06 ton/há, passando em 2010 para 0,32 ton/ha e atingindo em 2015 um valor de 0,26ton/ha. Desta forma, a vulnerabilidade da produção que predominavam na agricultura cearense é explicitada vis à vis o estímulo às outras que têm valor econômico de boa inserção internacional.

Tabela 5 - Produção de milho por área plantada (em hectares), Ceará, 2000 a 2015

\begin{tabular}{lccc}
\hline Ano & $\begin{array}{c}\text { Área plantada } \\
\text { Hectares }\end{array}$ & $\begin{array}{c}\text { Produção } \\
\text { Toneladas }\end{array}$ & $\begin{array}{c}\text { Produção } \\
\text { Toneladas/Hectare }\end{array}$ \\
\hline 2000 & 613.626 & 623.630 & 1,06 \\
2001 & 619.265 & 244.580 & 0,39 \\
2002 & 702.962 & 629.447 & 0,89 \\
2003 & 707.891 & 745.317 & 1,05 \\
2004 & 655.677 & 379.837 & 0,58 \\
2005 & 568.753 & 281.713 & 0,49 \\
2006 & 639.205 & 760.231 & 1,19 \\
2007 & 679.901 & 357.342 & 0,53 \\
2008 & 694.054 & 752.882 & 1,08 \\
2009 & 714.034 & 538.962 & 0,75 \\
2010 & 551.984 & 174.955 & 0,32 \\
2011 & 725.301 & 915.286 & 1,26 \\
2012 & 535.959 & 122.501 & 0,23 \\
2013 & 360.877 & 112.741 & 0,31 \\
2014 & 474.619 & 347.828 & 0,73 \\
2015 & 495.927 & 130.887 & 0,26 \\
\hline
\end{tabular}

Fonte: Elaboração Própria. PAM/IBGE (2000; 2015).

Em 2000, o Ceará produziu 623.630 toneladas, passando a apresentar em 2010 174.955 toneladas e caindo para 130.887 toneladas em 2015. No tocante à área plantada, seguiu-se a mesma dinâmica de queda em termos absolutos. Em 2000, o Ceará contou com uma área plantada de 613.626 ha, auferindo em 2010, 551,984 ha e chegando o último ano da série a apresentar um total de 495.927 ha. 


\section{A pecuária e sua distribuição mesorregional no Ceará}

Os movimentos de transformação da agropecuária cearense são percebidos adicionalmente na evolução do efetivo do seu rebanho. É importante ressaltar que o território deste estado do Nordeste teve sua incorporação econômica à dinâmica global no seu processo de formação econômica, pautada na economia do gado, o que deu a alcunha de "ciclo econômico do couro". Segundo Lima Júnior (2014), considerando os aspectos físicos, todo o território cearense estava adaptado a um vasto curral cujas sedes de fazendas criatórias deram origem às primeiras vilas e cidades.

Esta pecuária, de caráter extensivo, passou também por mudanças recentes significativas, pelo estímulo à criação de rebanhos mais adequados à natureza local e no bojo de ações de apoio ao pequeno criador.

No tocante à pecuária recente do estado do Ceará, os dados da Pesquisa Pecuária Municipal (PAM) mostram que no período de 2000/2010/2015 o estoque de bovinos elenca maior participação das respectivas mesorregiões analisadas nos anos 2000 (31,26\%), 2010 (29,31\%) e 2015 (29,45\%) nos Sertões Cearenses. Como é natural, dado o seu caráter eminentemente urbano, a que auferiu menor participação relativa foi a mesorregião Metropolitana de Fortaleza em 2000 (3,18\%), 2010 $(3,01 \%)$ e 2015 (3,42\%). A mesorregião dos Sertões se manifesta como a de maior tradição e condições físicas para a pecuária, sendo uma de suas vocações econômicas.

Tabela 6 - Participação relativa (\%) no efetivo de animais nas mesorregiões cearenses no período de 2000 a 2015 (Ceará=100)

\begin{tabular}{lcccccccc}
\hline Discriminação & Anos & Noroeste & Norte & Metropolitana & Sertões & Jaguaribe & $\begin{array}{c}\text { Centro- } \\
\text { Sul }\end{array}$ & $\begin{array}{c}\text { Sul } \\
\text { Cearense }\end{array}$ \\
\hline Bovinos & 2000 & 18,28 & 11,38 & 3,18 & 31,26 & 13,71 & 10,36 & 11,82 \\
& 2010 & 17,44 & 10,63 & 3,01 & 29,91 & 15,03 & 11,43 & 12,55 \\
& 2015 & 15,57 & 9,38 & 3,42 & 29,45 & 15,31 & 12,52 & 14,36 \\
\hline Suínos & 2000 & 33,13 & 13,01 & 3,03 & 27,75 & 6,11 & 7,79 & 9,18 \\
& 2010 & 35,99 & 14,29 & 3,41 & 23,19 & 6,96 & 6,58 & 9,56 \\
& 2015 & 40,02 & 11,93 & 3,73 & 16,64 & 10,35 & 6,96 & 8,38 \\
\hline Caprinos & 2000 & 26,04 & 9,81 & 1,24 & 39,80 & 15,34 & 3,21 & 4,56 \\
& 2010 & 27,69 & 10,44 & 1,03 & 36,16 & 16,75 & 3,26 & 4,66 \\
& 2015 & 25,53 & 9,98 & 1,11 & 35,11 & 19,52 & 3,48 & 5,28 \\
\hline Ovinos & 2000 & 17,81 & 8,78 & 1,19 & 47,19 & 17,36 & 4,07 & 3,60 \\
& 2010 & 18,27 & 9,59 & 1,43 & 45,89 & 17,38 & 3,42 & 4,02 \\
& 2015 & 15,94 & 9,07 & 1,67 & 41,83 & 20,70 & 5,31 & 5,57 \\
\hline
\end{tabular}

Fonte: Elaboração própria. PPM/IBGE (2000; 2010; 2015).

Para o Sul Cearense percebe-se aumento relativo do estoque bovino ao longo dos anos em estudo com 11,82\% em 2010, 12,55\% em 2010, 14,36\% em 2015 . O 
Noroeste Cearense segue dinâmica semelhante ao observar queda em termos relativos de bovinos, vindo atingir em 2015 um total de 15,57\%. No caso do Norte Cearense, percebe-se queda em termos relativos atingindo um estoque de 9,38\% em 2015.

No caso dos suínos, percebe-se que a mesorregião Noroeste Cearense tem crescente participação com 33,13\% em 2000, 35,99\% em 2010 e 40,02\% em 2015, alcançando dessa forma, a maior participação no estado do Ceará, enquanto a mesorregião Metropolitana apontou menor participação atingindo 3,73\% em 2015. Os Sertões Cearenses auferiram em 2000, 2010 e 2015 respectivamente 27,75\%, 23,19\% e $16,64 \%$. A mesorregião Jaguaribe, ao longo dos anos analisados, teve participação relativa crescente, vindo a atingir 10,35\% em 2015. Centro-Sul e Sul elencam a menor participação percentual auferindo 6,96\% e 8,38\%, respectivamente em 2015.

No caso dos caprinos, percebe-se novamente a proeminência da mesorregião Sertões Cearenses com a maior participação ao longo dos anos, apresentando $39,80 \%$ em 2000, 36,16\% em 2010 e vindo atingir 35,11\% em 2015. Na sequência, destaca-se a Noroeste Cearense que em 2015 participava com aproximadamente do total de $25,53 \%$ caprinos no estado. Estes números apontam para a especialização dos Sertões $25 \%$ na pecuária, conforme apontado anteriormente, tendo em vista o seu quadro físico e geográfico bem como as heranças históricas (CAMPOS; CAMPOS, 2013). Tais aspectos estimularam programas de apoio à agricultura familiar criatória de rebanhos de animais pequeno porte como caprinos e ovinos.

No que tange aos ovinos, os Sertões Cearenses também configuram como a mesorregião com maior participação relativa dentre as demais do estado do Ceará: no ano de 2000, ela detém participa com 47,19\%, caindo em 2010 para 45,89\% e vindo atingir em 2015 um total de 41,83\% do total de cabeças de ovinos estadual.

Desta forma, pela análise descritiva da dinâmica econômica agropecuária cearense e reforçada pelos dados, observa-se um gradativo ordenamento com a dedicação às áreas mais tradicionais como os Sertões Cearenses à criação de rebanhos mais adequados às características físicas e climáticas. Ademais, a valorização destes rebanhos como estímulo a novos mercados, bem como culturas de convivência com o Semiárido, tem disso estratégico como promoção de territórios com vocações mais tradicionais.

\section{Considerações finais}

O estado do Ceará passou no final dos anos 1980 por um ajuste no paradigma de regulação na gestão, pela emergência do modelo neoliberal pautado na eficiência pública e da austeridade fiscal para se alinhar ao macrocontexto de inserção produtiva internacional e romper o círculo vicioso de crônico atraso decorrente dos estrangulamentos físicos e sociodemográficos presentes em suas mesorregiões. 
Assim, houve um alinhamento dessa forma ao processo de abertura econômica, globalização dos mercados e ao redimensionamento do papel do Estado para amenizar o hiato que separa o Ceará dos estados mais desenvolvidos do Brasil.

No âmbito da agropecuária, este processo se propôs a um conjunto de modernização pautado principalmente na ótica da inserção competitiva e direcionamento para atividades econômicas que corroborassem tal intento.

O trabalho, ao analisar a dinâmica econômica do setor agropecuário cearense e sua evolução nos anos de 2000/2010/2015. Os principais resultados mostram que a mesorregião Jaguaribe Cearense configura como o maior subespaço de produção da fruticultura no estado, elencado como produtor quase que absoluto na produção de melão para exportação, gerando o maior volume de empregos formais no setor agropecuário $(39,39 \%)$.

No que tange à produtividade média das culturas, recorreu-se à análise das culturas mais voltadas ao mercado externo que são aquelas do ramo da fruticultura irrigada: melão e melancia e, de outro lado as culturas tradicionalmente cultivadas como feijão e milho. Os dados mostraram que as frutícolas analisadas obtiveram maior produtividade média, com destaque para a melancia, que passou de 3,84 ton/ha em 2000 para 25,74 ton/ha em 2015. No caso do feijão e do milho, ambas atingiram respectivamente 0,17 ton/ha e 0,26 ton/ha no último ano da série. Os resultados podem ser explicados pelos longos períodos de estiagem que vêm ocorrendo na região, diminuindo a produção na agricultura de sequeiro. Ademais, as culturas tradicionais estão sendo substituídas por aquelas de maior interesse do mercado externo. As mesorregiões Centro-Sul e Sul Cearenses pouco participam na produção agropecuária estadual, enquanto a mesorregião dos Sertões Cearenses tem na pecuária, notadamente na ovinocaprinocultura, uma base de estímulo à economia local.

Em síntese, percebe-se que as culturas tradicionalmente mantidas no Ceará (feijão, milho, aqui analisadas) vêm perdendo participação em detrimento do crescimento da fruticultura direcionada ao mercado externo (melão e melancia), indicando que a dinâmica do setor agropecuário cearense está mais voltada à inserção externa do que propriamente à transformação estrutural interna. $\mathrm{O}$ reordenamento econômico decorrente leva a considerar que a inserção competitiva é o veio condutor da reestruturação na dinâmica deste setor, induzindo poucas culturas de interesse deste desiderato e abandonando as mais tradicionais.

\section{Fonte(s) de Financiamento}

Coordenação de Aperfeiçoamento de Pessoal de Nível Superior (CAPES) e Fundação Cearense de Apoio ao Desenvolvimento Científico e Tecnológico (FUNCAP). 


\section{Referências}

ABLAS, L. Agricultura irrigada e desenvolvimento regional. Revista Econômica do Nordeste, vol. 19, n. 2, p. 155-174, abr.-jun./1988.

ARAÚJO, T. B. Nordeste, Nordestes: Que Nordeste? Ensaios sobre o desenvolvimento brasileiro (heranças e urgências). Rio de Janeiro: Fase, 2000.

BIELSCHOWSKY, R. O pensamento económico brasileiro: o ciclo ideológico do desenvolvimentismo. 5 ed. Rio de Janeiro: Contraponto, 2004.

BUAINAIN. A. M.; GARCIA. J. R. Desenvolvimento rural do semiárido brasileiro: transformações recentes, desafios e perspectivas. Confins, n. 19, 2013. Disponível em: https://confins.revues.org/8633?lang=pt. Acesso em: 19 jun. 2017.

CAMPOS, R. T.; K. C. CAMPOS. Diagnóstico técnico-econômico da ovinocapirnocultura no Estado do Ceará. Revista Teoria e Evidência Econômica, vol. 19, n. 40, jan.-jun./2013, p. 126-152.

CANO, W. Ensaios sobre a crise urbana no Brasil. Campinas: Ed. Unicamp, 2011.

CEPAL. Estudio económico de América Latina. Nova Iorque: Comissão Econômica para América Latina e Caribe; Organização das Nações Unidas, 1949.

CASTRO, C. N. A agricultura no Nordeste brasileiro: oportunidades e limitações ao desenvolvimento. Texto para discussão IPEA. Brasília; Rio de Janeiro: IPEA, 2012.

DANTAS, E. W. C. Construção da imagem turística de Fortaleza/CE. Mercator: Revista de Geografia da UFC, vol. 1, n. 1, p. 53-60, 2002.

DINIZ, C. C. Celso Furtado e o desenvolvimento regional. Nova Economia, vol. 19, n. 2, p. 227-249, mai.-ago.-2009.

EVANGELISTA, F. R. Vocação do Nordeste para a agroindústria. Revista Econômica do Nordeste, vol. 27, n. 2, p. 259-266, abr.-jun./1996.

GOMES, I. R. Globalização e novas regiões produtivas no Nordeste brasileiro. Mercator: Revista de Geografia da UFC, vol. 9, n. 20, p. 57-74. set.-dez./2010. 
GRAZIANO DA SILVA, J. A nova dinâmica da agricultura brasileira. 2 ed. Campinas: Unicamp/IE, 1998.

GRAZIANO DA SILVA, J. O novo rural brasileiro. Campinas: Unicamp/IE, 1999.

GTDN. Uma política de desenvolvimento econômico para o Nordeste. Recife: Sudene; Grupo de Trabalho para o Desenvolvimento do Nordeste, 1967.

IBGE. Rio de Janeiro: Instituto Brasileiro de Geografia e Estatística, 2010. Disponível em: http://www.ibge.gov.br. Acesso em: 28 jun. 2017.

IBGE. Pesquisa pecuária municipal e produção agrícola municipal, 20002015. Rio de Janeiro: Instituto Brasileiro de Geografia e Estatística, s.d. Disponível em: http://www.ibge.gov.br. Acesso em: 28 jun. 2017.

IBGE. Censo agropecuário, 2006-2007. Rio de Janeiro: Instituto Brasileiro de Geografia e Estatística, s.d. Disponível em: http://www.ibge.gov.br. Acesso em: 28 jun. 2017.

IPECE. Fortaleza: Instituto de Pesquisa e Estratégia Econômica do Ceará, 2015. Disponível em: http://www.ipece.ce.gov.br. Acesso em: 28 jun. 2017.

LIMA JÚNIOR, F. O. Estrutura produtiva e rede urbana no Estado do Ceará durante o período de 1980-2010. Campinas. 2014. 264p. Tese (Doutorado) Unicamp /IE, 2014.

LIMA, J. P. R. Traços gerais do desenvolvimento recente da economia do Nordeste. Revista Econômica do Nordeste, vol. 36, n. 1, jan.-mar./2005.

MADEIRA, S. A. A análise da modernização agrícola cearense no período de 1996 e 2006. Fortaleza. 2012. 92 p. Dissertação (Mestrado) - Universidade Federal do Ceará, 2012.

SECEX. Estatísticas de comércio exterior. Brasília: Secretaria de Comércio Exterior/Ministério da Indústria e Comércio, s.d. Disponível em: http://www.mdic.gov.br/index.php/comercio-exterior/estatisticas-de-comercioexterior/balanca-comercial-brasileira-unidades-dafederacao?layout=edit\&id=1187. Acesso: 12 dez. 2017.

MOURA, J. E.; PAIVA. M. J. Escolaridade e rebatimentos nos rendimentos do trabalho formal agropecuário: Ceará e Rio Grande do Norte, 2002/2012. In: VIII Encontro SOBER Nordeste. Anais... Mossoró/RN, 2016. 
MULLER, G. Agricultura e industrialização do campo no Brasil. Revista de Economia Política, vol. 2, n. 6, p. 47-67, abr.-jun./1982.

PACHECO, C. A. Fragmentação da nação. Campinas: Unicamp/IE, 1998.

RAIS. Relação Anual de Informações Sociais, 2015. Disponível em: http//www.mte.gov.br. Acesso em: 28 jun. 2017.

RAMOS, P. Dimensões do agronegócio brasileiro: políticas, instituições e perspectivas (= NEAD Estudos, 15). Brasília: MDA, 2007.

SILVA FILHO, L. A. Distribuição espacial da indústria: fases e fatos no contexto dos anos 2000. Revista Economia \& Tecnologia, vol. 10, n 2, p. 107-130, abr.jun. 2014.

SILVA, J. G. A nova dinâmica da agricultura brasileira. 2 ed. Campinas: Unicamp/IE, 1998.

SILVA, R. M. A. Entre dois paradigmas: combate à seca e convivência com o semiárido. Revista Sociedade e Estado, vol. 38, n. 1-2, p. 466-485, jul./set. 2003.

SOUSA, E. P. Impactos da formação especial de preços na fruticultura irrigada do Ceará. Viçosa. 2010. Tese (Doutorado) - Programa de Pós-Graduação em Economia Aplicada/UFV, 2010.

VALOIS, I. S. Caminhos da convergência da renda agropecuária no Brasil: uma análise a partir do processo de markov de primeira ordem para o período de 1996 a 2009. Fortaleza. 2012. 94f. Dissertação (Mestrado em Economia Rural) MAER/UFC, 2012.

VALE, F. F. R.; SILVA FILHO, L. A.; SILVA, J. L. M. Modernização agrícola e emprego formal: notas para o Ceará, Pernambuco, Nordeste e Brasil. V Encontro SOBER Nordeste. Anais... Crato/CE, 2010. 
Data de submissão: 20/08/2019

Data de aprovação: 20/10/2020

Revisão: Daniela Matthes (português), Anderson de Miranda Gomes (inglês) e Yanet María Reimondo Barrios (espanhol).

José Ediglê Alcântara Moura

Economista

Avenida Mister Hull, 2977 - Bairro Antônio Bezerra

60.440-970 Fortaleza/CE, Brasil

Orcid: http://orcid.org/0000-0003-1285-7717

E-mail: edigle.economia@gmail.com

Francisco do O' de Lima Júnior

Departamento de Economia / Universidade Regional do Cariri

Rua Coronel Antônio Luis, 1161 - Pimenta

63105-000 Crato/CE, Brasil

Orcid: http://orcid.org/0000-0002-6049-3893

E-mail:lima.junior@urca.br

Denis Fernandes Alves

Economista

Rua Professor Antônio Campos, s/n - BR 110, km 48 - Bairro Costa e Silva

59600-000 Mossoró/RN, Brasil

Orcid: http://orcid.org/0000-0003-3322-2075

E-mail: denis_fernandes@outlook.com 